\title{
A Return on Investment as a Metric for Evaluating Information Systems: Taxonomy and Application
}

\author{
Alexei Botchkarev \\ Ministry of Health and Long- \\ Term Care \& \\ Ryerson University, \\ Toronto, Ontario, Canada
} alexei.botchkarev@ontario.ca

\author{
Peter Andru \\ Ministry of Health and Long- \\ Term Care, \\ Toronto, Ontario, Canada
}

\begin{abstract}
Return on Investment (ROI) is one of the most popular performance measurement and evaluation metrics used in business analysis. ROI analysis (when applied correctly) is a powerful tool for evaluating existing information systems and making informed decisions on software acquisitions and other projects. Decades ago, ROI was conceived as a financial term and defined as a concept based on a rigorous and quantifiable analysis of financial returns and costs. At present, ROI has been widely recognized and accepted in business and financial management in the private and public sectors. Wide proliferation of the ROI method, though, has lead to the situation today where ROI is often experienced as a non-rigorous, amorphous bundle of mixed approaches, prone to the risks of inaccuracy and biased judgement.

The main contribution of this study is in presenting a systematic view of ROI by identifying its key attributes and classifying ROI types by these attributes. ROI taxonomy has been developed and discussed, including traditional ROI extensions, virtualizations, and imitations. All ROI types are described through simple real life examples and business cases. Inherent limitations of ROI have been identified and advice is provided to keep ROI-based recommendations useful and meaningful.
\end{abstract}

The paper is intended for researchers in information systems, technology solutions, and business management, and also for information specialists, project managers, program managers, technology directors, and information systems evaluators.

Keywords: Return on Investment, ROI, evaluation, limitations, taxonomy, information system, performance measure, business value.

Material published as part of this publication, either on-line or in print, is copyrighted by the Informing Science Institute. Permission to make digital or paper copy of part or all of these works for personal or classroom use is granted without fee provided that the copies are not made or distributed for profit or commercial advantage AND that copies 1) bear this notice in full and 2) give the full citation on the first page. It is permissible to abstract these works so long as credit is given. To copy in all other cases or to republish or to post on a server or to redistribute to lists requires specific permission and payment of a fee. Contact Publisher@,InformingScience.org to request redistribution permission.

\section{Introduction}

Public attention to ROI has a clear dependency on the state of the economy. Rough times bring about tougher competition of projects for available dollars and spur the interest of academics and practitioners in evaluation methods, and ROI is a significant tool. 
A renewed focus on ROI can be observed today, including using ROI as a buzzword to confound understanding rather than clarify meaning. A Google search brings back millions of hits which mention ROI. New pages and updates appear at a staggering speed of increase of thousands every 24 hours. An even more specific Google search for an "ROI calculator" shows over several hundred thousand pages. The number grows several times every year. The abbreviation "ROI" is arguably one of the most frequently used business abbreviations, now often used without spelling it out.

So, while the term is popular, there are completely different views concerning its use.

One view is that ROI is "the most popular" metric to use when comparing the attractiveness of one information technology (IT) investment to another. ROI is a key metric used by CIOs to help quantify the potential success of an IT or business project ("Return on investment," n.d.).

The other view is to "forget ROI. The best, most innovative IT improvements have no ROI. There was no decent ROI on installing the first Wang word processor in the 1970s or the first PC to run VisiCalc in the 1980s or the first Linux server for corporate Web sites in the 1990s. ... If we let the ROI Wormtongues rule the day, this decade will never see an analogue to the technological achievements of past decades. ... wisdom can't be reduced to an ROI calculation" (Hall, 2003).

While those are two extreme views on the use of ROI, there are dozens of views somewhere in between them. This diversity of opinion is what stimulated this study to review the current state of the issue and help provide greater understanding of ROI and its application.

\section{What is ROI?}

According to the Investopedia, ROI is a performance measure used to evaluate the efficiency of an investment or to compare the efficiency of a number of different investments. To calculate ROI, the benefit (return) of an investment is divided by the cost of the investment; the result is expressed as a percentage or a ratio ("Return on Investment - ROI," 2011.).

The return on investment formula:

$$
\mathrm{ROI}=\frac{\text { Gain from Investment }- \text { Cost of Investment }}{\text { Cost of Investment }}
$$

There are many other ROI definitions in the literature (e.g., "Rate of Return," n.d.; Goetzel, n.d.). Each definition focuses on certain ROI aspects. Such definitions reflect the fact that approaches to ROI and even ROI concepts vary from company to company and from practitioner to practitioner; most likely every consultant has a particular variation. Despite the diversity of the definitions, the primary notion is the same: ROI is a fraction, the numerator of which is "net gain" (return, profit, benefit) earned as a result of the project (activity, system operations), while the denominator is the "cost" (investment) spent to achieve the result.

However, in some publications, the numerator in the ROI formula is equal to the project "gain" (not gain minus cost) (Mogollon \& Raisinghani, 2003). Usually, this metric is called benefit-cost ratio. It should be noted that in such cases the results of the calculations have a different meaning. For example, ROI of $100 \%$ means that the amount of the return equals the amount of the money invested - no additional money was gained. A more common sense use of the above formula, one hundred percent ROI means not only the return of the money invested but also gaining the same amount as profit. 
The definition from Investopedia treats ROI as a measure / metric / ratio / number. In some cases, return on investment is understood as a "method" or "approach" - "ROI analysis". In this meaning, ROI or "ROI Analysis" includes not only an "ROI ratio" but also several other financial measures (e.g., internal rate of return - IRR, net present value - NPV, payback period, etc.), which are collectively called "ROI" (Mogollon \& Raisinghani, 2003). Further, within this approach some articles may read, "ROI is three months" That would mean that ROI analysis has been performed and a payback period indicator was used, which was calculated to be 3 months. In specific situations, ROI variations can be used: Return on invested capital, return on total assets, return on equity, return on net worth (Andolsen, 2004).

Finally, return on investment may be understood as any kind (financial or non-financial) of return / effect / result or general business impact/value.

This paper is focused on ROI as an individual measure. Other measures of the ROI analysis are referred to as ROI-related measures and are not included in the primary scope of work.

The purpose of ROI varies and includes:

1. Providing a rationale for future investments and acquisition decisions:

- Project prioritization/ justification.

- Facilitating informed choices about which projects to pursue (which solutions to implement).

2. Evaluating existing systems.

- Project post-implementation assessment.

- Facilitating informed decisions within the process of evaluating existing projects/solutions.

3. Performance management of the business units and evaluation of the individual managers in decentralized companies:

- Often called the Du Pont method - by the name of the company which first implemented it - and considered a default standard in the 1960-70s. The method has been analyzed in John Dearden's article published in the Harvard Business Review (Dearden, 1969). The title of the article is very revealing: "The case against ROI control." The article indicates a wide spread of the ROI method and frequent incorrect use of the measure. It is stated that "ROI oversimplifies a very complex decision-making process." This type of ROI use is out of scope for this paper.

Some authors look at ROI evaluations even broader: as a method of persuasive communication to senior management, a process of getting everybody's attention to the financial aspects of the decisions and stimulating a rigid financial analysis. In this case, actually calculated ROI numbers are of less importance compared to the processes of gathering/analyzing cost and benefit data (Kalvar, 2003).

ROI popularity is due to many objective and subjective reasons.

Objective Reasons for ROI Popularity:

- Anecdotal evidence of successful use.

- $\quad$ Easy to understand and straightforward.

- $\quad$ Easy to compute.

- Encourages prudent detailed financial analysis. 
- Encourages cost efficiency and focuses on one of the main corporate metrics - profitability.

- Being based on the accounting records, provides objective outputs.

- Data used is available in the accounting system or official documentation.

- Permits comparisons of profitability of dissimilar businesses/projects.

- Promotes accountability. Transparent collection and use of official financial data contributes to responsible behaviours of those involved in data collection and evaluations.

- Encourages project teams and finance/accounting practitioners to collaborate.

Subjective Reasons for Traditional ROI Popularity:

- Seems familiar from college textbooks.

- Feels familiar from personal investment experience.

- Seemingly easy to collect and process data.

- Use of data and math makes creates anticipation of an accurate and definitive result.

- $\quad$ Single number result - simplifying for the mind.

- Provides quantifiable evidence of value.

- $\quad$ Single measure offers a seemingly global evaluation of performance.

Another driving force is the interest of certain business groups and C-level individuals. Chief Information Officers (CIOs) favor the use of ROI because that's the way to show that IT departments are profit centers, not just cost centers, as it may seem when total cost of ownership (TCO) is used as a metric (Ryan \& Raducha-Grace, 2009).

\section{Purpose of the Paper}

The preliminary information search on ROI retrieved hundreds of academic and business publications describing many ROI types, and hundreds of versions. Multiple interpretations of what ROI is, and how it should be calculated lead to arguments between the authors on what's right and wrong. The approach of this paper is to avoid getting into this "right or wrong" discussion, but to take a systematic view of the ROI by identifying its key attributes and grouping/classifying ROI types by these attributes. An ROI taxonomy has been developed and is discussed.

Each section of the paper details a specific ROI type and provides simple real life examples and business cases to show a variety of ROI properties and its applications.

The scope of this study is defined by the following:

- A high-level business analysis is presented. The level of discussion is aligned with the common approach of the project teams' evaluation of information systems. No accounting details are addressed, e.g., cost of taxes on savings or depreciation of the assets.

- $\quad$ ROI is presented at a conceptual level. Issues of implementing processes of ROI assessments are out of the scope of this paper.

- Most considerations are applicable to both private and public sectors (Al-Raisi \& AlKhouri, 2010; Chmielewski \& Phillips, 2002; Phillips \& Phillips, 2006; National Association of Chronic Disease Directors, 2009).

- Most considerations of ROI use are generic and applicable in any field. However, the focus is strongest on Information Systems/Solutions. Information systems are understood 
as integrated complexes which include computers (hardware, software), means of communication, people, and business processes, e.g., Enterprise Resource Planning (ERP) or Customer Relationship Management (CRM) systems. Evaluation and implementation of such systems have certain differences from "pure" information technology (IT) projects (e.g., replacing individual physical servers with virtual servers or a switch from desktops to laptops, which have minimal impact on end-users and don't require re-engineering of the business processes).

- $\quad$ Further, there is no description of specific sub-areas of ROI use, e.g., ROI of social media (Petouhoff, 2009), ROI of e-business (Mogollon \& Raisinghani, 2003), ROI of user experience (Hirsch, Fraser, \& Beckman, 2004), ROI of learning programs (Haddad, 2011; Kingma \& Schisa, 2010), ROI of knowledge management (McManus, Wilson, \& Snyder, 2004), ROI of records and information management (Andolsen, 2004), ROI of quality initiatives (Coelho \& Vilares, 2010), and ROI of websites and search ("Maximizing website return on investment," 2009). All of the mentioned areas have their own specific measures of the benefits and costs, the description of which would obscure the demonstration of the main ROI qualities and characteristics.

- Lastly, the ROI method is just one of many metrics for evaluating information systems. There are a dozen other popular financial measures, and even more metrics of different types. Some of these metrics are briefly mentioned in the Discussion Section. This paper is focused on ROI and all other metrics are out of the scope of this paper.

The literature review has shown that prior papers on ROI have treated the ROI method as a single-formula tool complicated by a number of disparate features and characteristics used randomly by various groups of researchers and practitioners. The main contribution of this study is in presenting a systematic view of ROI by identifying its key attributes and classifying ROI types by these attributes. An ROI taxonomy has been developed and discussed, including traditional ROI, extensions, virtualizations, and imitations. The presented taxonomy allows for a meaningful selection of the ROI type most appropriate for a certain situation. A systematic approach to ROI leads to a new view of ROI results - a set of numeric parameters (not a single number). Also, ROI sensitivity to error has been analyzed on the sample case.

The paper is intended for researchers in information systems, technology solutions, and business management, and also for information specialists, project managers, program managers, technology directors, and information systems evaluators. These categories of the IJIKM readership are dealing with ROI assessments within their every day responsibilities, and the paper is intended to help these groups at the level they are involved in this matter and using terminology familiar to them.

\section{Traditional ROI}

The main attributes of the Traditional ROI are shown in Table 1. Notable points are:

- Traditional ROI is calculated in retrospective.

- Accounting records, e.g., official financial documents or accounting systems, are used as sources of cost and return data. That provides for full transparency of the ROI numbers and accountability of the staff that is performing assessments.

- It's about real money. Both - money invested (spent to deliver and maintain the system) and money organization gets back as financial returns. 


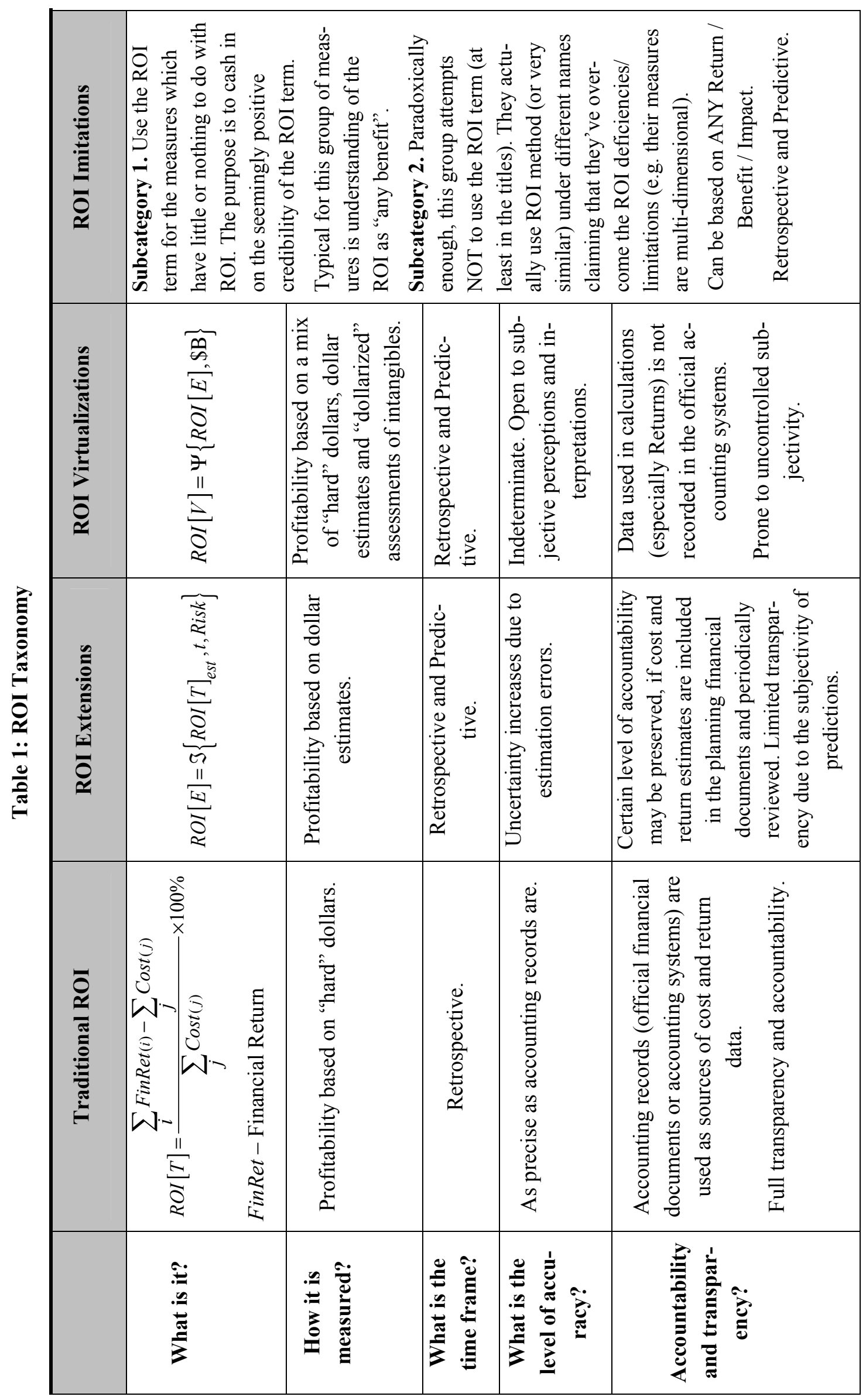


Tables 2 and 3 show typical components of costs and financial returns used in calculating Traditional ROI.

Costs usually are considered an easier part of the calculation. Notably, costs presented in the table are "real" dollars. All amounts are documented in the accounting records and can be supported by signed agreements, memorandums of understanding, contracts, journals, etc. Financial staff is heavily involved in its retrieval and processing.

Based on the numbers from the Tables 2 and 3 ROI for the scenario is $15.5 \%$.

It needs to be noted that ROI is a number in the range from $+\infty \%$ (infinity) for an outstanding results, down to $-100 \%$ for a project losing money. ROI $=-100 \%$ means that the project had only costs/investments (all of them used) and no returns. ROI cannot go lower than $-100 \%$ because of the notion that one cannot lose more than has been invested.

Table 2: Typical ROI Components - Costs

\begin{tabular}{|c|c|c|}
\hline Cost Component & Description & Sample Amount \\
\hline IT Infrastructure & $\begin{array}{l}\text { Software/Licenses - initial and annual maintenance. } \\
\text { Hardware - if IS run in-house (e.g., purchasing and installa- } \\
\text { tion of new servers). } \\
\text { Hosting - if IS provided as Software as a Service by a third } \\
\text { party. }\end{array}$ & $\begin{array}{c}\$ 100,000 \\
- \\
\$ 75,000\end{array}$ \\
\hline Labour & $\begin{array}{l}\text { Direct Operating Expenses (DOE). Salaries and Wages plus } \\
\text { Benefits for full time equivalent positions (FTEs) - jour- } \\
\text { naled to I\&IT Department. } \\
\text { Consultant Services (ODOE). FFS. - Installation, configura- } \\
\text { tion, software customization, integration that requires skills } \\
\text { not available within the I\&IT Department. }\end{array}$ & $\$ 230,000$ \\
\hline Training & $\begin{array}{l}\text { IT personnel training by a third party. } \\
\text { - } \\
\text { Program area end-user training by a third party. }\end{array}$ & $\begin{array}{l}\$ 10,000 \\
\$ 15,000\end{array}$ \\
\hline
\end{tabular}

Table 3: Typical ROI Components - Financial Returns

\begin{tabular}{|c|c|c|}
\hline $\begin{array}{c}\text { Return Compo- } \\
\text { nent }\end{array}$ & Description & Sample Amount \\
\hline Cost Savings & $\begin{array}{l}\text { - Three FTEs reduced - Salaries and Wages plus Benefits for } \\
3 \text { FTEs }\end{array}$ & $\$ 210,000$ \\
\hline Cost Avoidance & $\begin{array}{l}\text { Hiring of Two FTEs (which was planned to operate the old } \\
\text { system) was halted - Salaries and Wages plus Benefits for } 2 \\
\text { FTEs }\end{array}$ & $\$ 140,000$ \\
\hline $\begin{array}{l}\text { Increased reve- } \\
\text { nues }\end{array}$ & - $\quad$ Increased sales, or sales margins & $\$ 50,000$ \\
\hline $\begin{array}{l}\text { Revenue en- } \\
\text { hancement }\end{array}$ & $\begin{array}{l}\text { - Additional revenues were gained due to better targeted mar- } \\
\text { keted and advertising }\end{array}$ & $\$ 250,000$ \\
\hline $\begin{array}{l}\text { Revenue protec- } \\
\text { tion }\end{array}$ & $\begin{array}{l}\text { - Imminent fine was avoided (due to demonstrated compliance } \\
\text { with regulatory requirements) }\end{array}$ & $\$ 20,000$ \\
\hline
\end{tabular}


If the number was less than zero, more money would be invested than earned due to this project, and the result would be a so-called "negative" ROI. Many college text books provide clear and "simple" advice for such situations - projects with negative ROI shouldn't be undertaken. We'll return to this case later to see whether the advice is simple or simplistic.

Although ROI is a ratio usually measured in percent, when the ROI analysis is completed a question may arise concerning the result in terms of dollars. In the case of Traditional ROI, the answer is clear: all numbers are taken from the accounting records (accounting systems), so we know for sure where (which account) we should go to for a "surplus". In this case, dollars are real, hard, or capturable. We can "take"/transfer this money and use it elsewhere. This is true even in the case of cost avoidance. The company (in the case illustrated in Table 2) knew that it needed to hire two (2) new full-time employees, so the payroll funds were allocated. Or in the case of revenue protection, the company knew it would be fined, so certain amounts were allocated in the financial plan for that.

All numbers can be checked and validated after the project is completed and at any point during operations. The responsibility of the staff who worked with the numbers and the ROI calculations is transparent. This fact ensures good discipline.

An important point is that there's no standard for ROI calculations. There's only general advice to include (address) "all" costs and financial returns attributable to the solution/project. This guiding rule seems to be very straightforward. However, just after the first "obvious" components are included (hardware, software, etc.) questions start to emerge, for example:

- Case 1. Two solutions are compared. The first is run in-house (so all infrastructure costs apply). The second is a Software as a Service (SaaS) or a cloud application. Obviously, "cloud" solutions will have an advantage in terms of ROI. Is it correct? Building an in-house infrastructure has its own value (like greater flexibility, in-house expertise, etc.). There are no rules to deal with these issues (or they are outside the ROI area).

- Case 2. A company already has an in-house solution. Now a new application hosted outside is offered by another vendor. As in the first case a new solution will look more attractive in ROI terms. However, a key question arises: how do you account for the cost of the existing hardware (and prior investments in it)? As an asset it can be sold or used for other applications. Where in the ROI calculations would you put it and has anybody actually accounted for it in the ROI assessment?

Actually, following the simplistic ROI-logic in the previous cases and taking it to an extreme, everything should be taken to the cloud and internal IT departments should be eliminated. Hopefully, not everybody is taking this direction after a first glance at particular ROI results.

Although the amounts of the costs and returns in the Traditional ROI are taken from official accounting records, what type of costs or returns to include is based on human judgment and may be biased. In ROI of other types this drawback is getting worse because not only what type of costs to include becomes a matter of judgment, but also the amounts/values are results of "estimates" and forecasting. That keeps the door open for subjectivity.

In order to illustrate ROI properties, let's consider a case of choosing between two projects. Let's assume that for each project we have absolutely correctly calculated ROI numbers: Project A with $\mathrm{ROI}=7 \%$ and Project $\mathrm{B}$ with $\mathrm{ROI}=70 \%$. Which one to choose/approve? The answer seems to be obvious. But what if Project B has project risk (probability of success) of 0.1 (destined to fail) and Project A - 0.95 (almost sure to happen)? Now the answer is not so obvious. (Please note that the terms of this and the next example go a bit beyond the scope of the pure traditional ROI. This has been an intentional stretch to consolidate a description of inherent ROI properties.) 
Let's continue with this case and use the same projects as above with the same ROIs; also let's assume projects have equal risks. Again, ROI logic provides a simple answer - choose project "B". However, what if costs and net returns for "B" are $\$ 300,000$ and $\$ 21,000$ and for " $A$ " are $\$ 10,000$ and $\$ 7,000$ ? That means that the net return of the project " $\mathrm{B}$ " is three times lower than for project "A". Would project "B" still be the favourite?

It's easy to "unveil" several other business case parameters (e.g., gross investments needed or payback period) and with each parameter being added an "obvious" ROI-based decision may be questionable, if not completely wrong.

This example demonstrates that ROI being presented as a single number, as it is often presented in articles or business presentations, has many uncertainties which make the single number actually meaningless.

To provide a reliable and meaningful context for business decisions, the ROI number must be accompanied with a detailed description of the terms, conditions, and assumptions under which the ROI calculations were conducted and at least 5 to 10 additional numeric characteristics of the ROI business case. When ROI is provided as a single number, it doesn't mean that those who perform analysis don't know about other factors. They just "assume" that all other factors are the same for the compared projects.

Some inherent ROI limitations include:

- $\quad \mathrm{ROI}$ is a ratio:

- ROI focuses on maximizing the return-investment ratio and fails to guide towards profit maximization.

- ROI analysis doesn't incorporate means to evaluate projects based on the viability of the gross investments needed (estimate availability of funds).

- ROI analysis has no means to demonstrate alignment with the organization's business strategy and/ or regulatory compliance.

- ROI analysis tends to focus on individual projects and has no facilities for an integrated look at the projects/systems' interdependencies and overarching systems view.

- ROI is a financial measure, focused on profitability.

- ROI doesn't tell anything about systems' effectiveness (how good is the system at what it is supposed to be doing), nor about systems' efficiency (what the system is doing per dollar).

In the preceding cases, it was demonstrated that even in rather simple situations ROI analysis may lead to questionable, if not completely wrong, results and recommendations. ROI is a metric designed for a certain purpose - to assess profitability or financial efficiency. There are many other aspects of financial "health" of the organization. That's why there are a couple of dozen financial metrics used. In general, ROI cannot be used as a single or principal metric for evaluating complex information systems, such as ERP or CRM.

\section{ROI Extensions}

ROI Extensions have been created with the purpose of fixing some deficiencies of the Traditional ROI and widening the area of ROI use. Please refer to Table 1 for the main attributes of this ROI type. Traditional ROI is calculated in retrospective - for the projects that have been already completed. The main differentiator of the ROI Extensions is that they are calculated for future projects (although past periods may be included). The same final formula (net returns divided by 
costs) is used. The same types of costs and returns are included. However, for future projects costs and benefits cannot be acquired from accounting records. Their amounts are predicted through estimation processes. Also, ROI Extensions are often based on an inclusion of the time value of money, and the impact of risks.

\section{Estimating Costs}

In the previous section (Traditional ROI), costs and returns numbers were gathered or retrieved from accounting nnt Value:

$$
\mathrm{PV}=\mathrm{FV} /(1+\text { Rate })^{\mathrm{n}}
$$

- $\quad$ Rate - discount rate; the same as an interest rate;

- $\quad \mathrm{n}$ - Number of periods.

According to Forrester Consulting, organizations typically use discount rates between $8 \%$ and $16 \%$ based on their current environment (North, 2009). Time-adjusted present values can be seriously different from the future values. For example, in a 5-year project with $10 \%$ discount rate and future values of $\$ 1,000$ each year, time-adjusted values for the second to fifth years will be: $\$ 909, \$ 826, \$ 751, \$ 683, \$ 621$. As a result, amounts of the ROI calculated using time-adjusted costs and returns will also differ from "simple" ROIs.

\section{Another Time-Related Issue is Calculation of the Multi-Period ROI}

This can be tricky because there's no standard and consensus on ROI calculations. For example, consider a three-year project (see Figure 1). Overall (3-year) project costs equal 60, returns amount to 90 (million or thousand). ROI calculations can be delivered in four different ways, which are shown as rows in the table. Three middle columns of the table show how costs and returns are distributed between the years. The right column presents results of the ROI calculations for each of the four scenarios. Each of the scenarios is explained below. To simplify calculations, the time value of money is not factored in.

Scenario 1. Calculating ROI based on the total 3-year numbers results in ROI1 $=50 \%$.

Scenario 2. Same overall numbers $(90-60)$, but they are provided annually and distributed evenly over the years $(30-20)$, and calculations are done for each year and then summed up. Result: ROI $2=150 \%$. Some vendors and consultants would recommend this approach to calculations.

Scenario 3. Same overall numbers (90 - 60) provided annually but distributed differently, and calculations are done for an individual year and then summed up. Result: ROI3 $=450 \%$.

This method of calculations prompts the following behavior in order to maximize the ROI amount. Shift maximum costs to the year where the ROI will be negative (most likely the first year) because anyway the ROI will not go below $-100 \%$. Shift most benefits to the year with max returns - ROI will be multiplied.

Scenario 4. Same as Scenario 3 as far as year by year returns and costs. However, calculation is done based on the cumulative numbers, that is, cumulative return for a year equals to the sum of this year and previous years.

This example illustrates that ROI for a project with the same total numbers can be calculated in a variety of ways and provide totally different results (with order of magnitude variances). So, the ROI number can be confusing without a lot of details clearly depicting how it has been calculated. 
The actual amount of money gained in each of the scenarios is the same - 30 (not including cost of borrowing, taxes, etc).

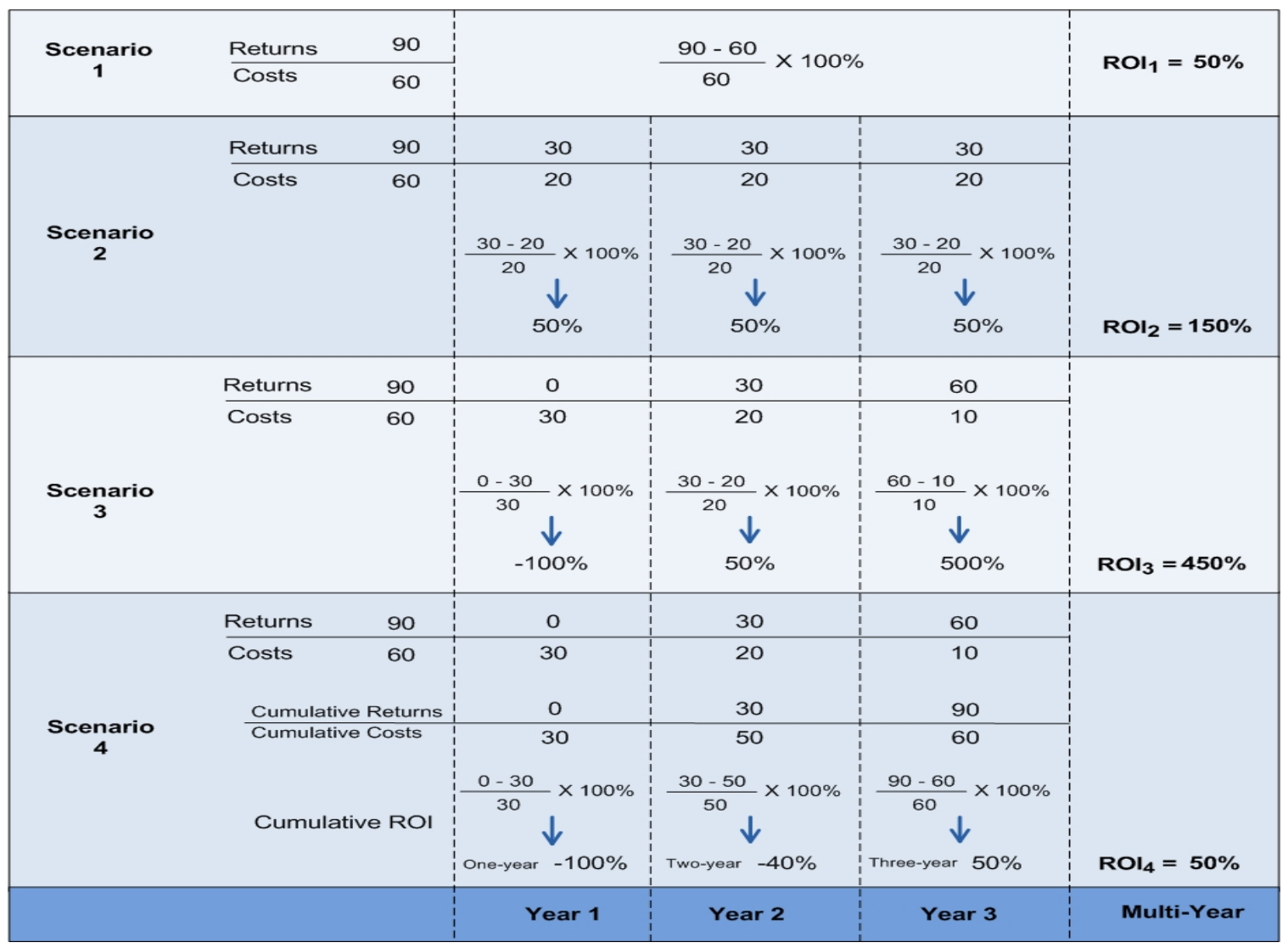

Figure 1: Multi-period ROI Calculations

Showing these examples, we are not advocating any of the approaches (what's right and what's wrong). We want to raise awareness of what is used so that you can be aware of which questions to ask when you are presented with multi-period ROI calculations.

Speaking about the time frame, the most fundamental question is how many years should be included in the calculations: 1 or 2 or 3 or the life cycle? There is no consensus on this issue. That's why this parameter must be explicitly provided with the ROI number (otherwise, ROI number is absolutely unclear).

\section{Risks in the ROI Context}

As soon as we start describing future projects, we need to take into account uncertainties. A risk is an event or condition that, if it occurs, has a positive or negative effect on costs or financial returns of the initiative. Positive risks are those events that lead to the decrease of costs and/or increase of financial returns. Negative risks are those events that lead to the increase of costs and/or decrease of financial returns. Many things can go wrong on a project - and some of them may affect costs or returns.

For examples, a project involving a deep customization of a new type of software performed by external consultants may result in an extension of the needed consultants' hours and, hence, an increase of costs and decrease of ROI. For example, there is a risk of 2-month overrun of the activity with probability 0.5 . 


\section{Risk-Adjusted Cost $=$ Initial Estimate $+0.5 \times(2$-month labour cost $)$}

Based on the PERT approach calculations are performed according to the formula:

(best case + worst case $+4 \mathrm{x}$ most likely case estimates) / 6

Identification of ROI risks should start from analyzing the general project risks and then focus on those "related" risks plus adding some specific ROI risks. The process is not very objective. Accuracy of the estimates is difficult to define.

\section{ROI Error Sensitivity}

As it was mentioned, public perception of ROI is that it is an accurate tool based on mathematical formulae. At the same time, we know that many assumptions about costs, returns, timeline, environment, etc. need to be made to calculate ROI. Naturally, ROI is as accurate as are the estimates of the costs, returns, and timelines that are used in the formula.

According to project management methodology, accuracy of estimates depends on the phase of the life cycle of the initiative. Usually, for the initiation phase accuracy is estimated as rough order of magnitude (ROM) - range of $+/-50 \%$. Later it could narrow to the range of $+/-10 \%$. Also, estimates of each type of costs and returns are associated with a certain level of accuracy.

Let's consider the effects of estimating errors on ROI accuracy on a simple example. The scenario: costs - $\$ 500,000$; returns - $\$ 600,000$. So, ROI $=20 \%$.

If we estimated Costs as X1 and real costs are X2, and we made an error (e.g., due to uncertainty of future vendor prices), which can be characterised by the absolute error Delta $=\mathrm{X} 1-\mathrm{X} 2$ or relative error Delta/X1 (which will be used in the scenario below), this error will then affect the ROI magnitude - so called propagation of uncertainty.

Let's assume that in our estimates/calculations of costs and/or returns we made a relative error of $+/-10 \%$, e.g. the absolute error for the costs will be from 0 to 50,000 . That magnitude of error may be experienced as the project progresses to its late life cycle phases (Project Management Institute, 2008).

What will be the amount of ROI, if we factor in the errors?

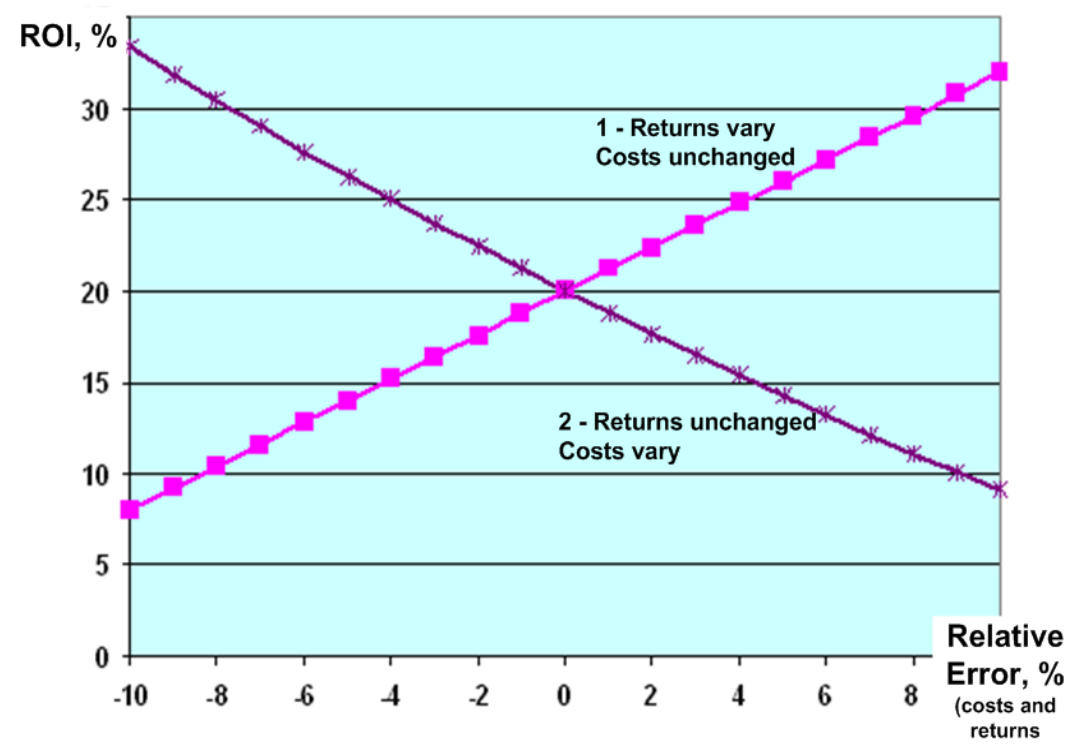

Figure 2: ROI Sensitivity to Error 
Figure 2 shows a diagram with two lines: Line 1 shows ROI for the case when costs were predicted with zero error and the relative error for the returns changes from $-10 \%$ to $+10 \%$; Line 2 shows ROI for the case when returns were predicted with zero error, and the relative error for the costs changes from $-10 \%$ to $+10 \%$. For these cases, ROI (from originally estimated $20 \%$ ) is floating in the range from 8 to $33 \%$.

The effect of the errors will be maximized, when the returns errors would be negative $(-10 \%)$, and costs errors would be positive $(+10 \%)$. This is illustrated in Figure 3. ROI range is getting even broader from $-2 \%$ to around $50 \%$ and more difficult to be called "highly accurate." Note that at some "worst case" point, ROI becomes "negative" (from an initial "true" ROI of $20 \%$ ).

Observations from this exercise:

- ROI is not immune from errors. Unavoidable uncertainties/errors of estimating costs and returns propagate through the ROI formula and affect the result.

- "Precise" ROI is more an exception than the rule. Results of the ROI calculations with decimal places are most likely questionable.

- For prudent analysis, an ROI number should be accompanied with characteristics of the accuracies of costs and returns estimates and evaluation of the accuracy of the final ROI number.

The value of this exercise is in the demonstration of the approach and illustration of the level of the ROI accuracy for a typical CRM project. Although performed on a specific example and not claiming any generic value, it has shown that even relatively low-level errors of estimating costs and returns $(+/-10 \%)$ may lead to significant ROI inaccuracies. To make a ROI number meaningful, it should be provided with an assessment of its accuracy.

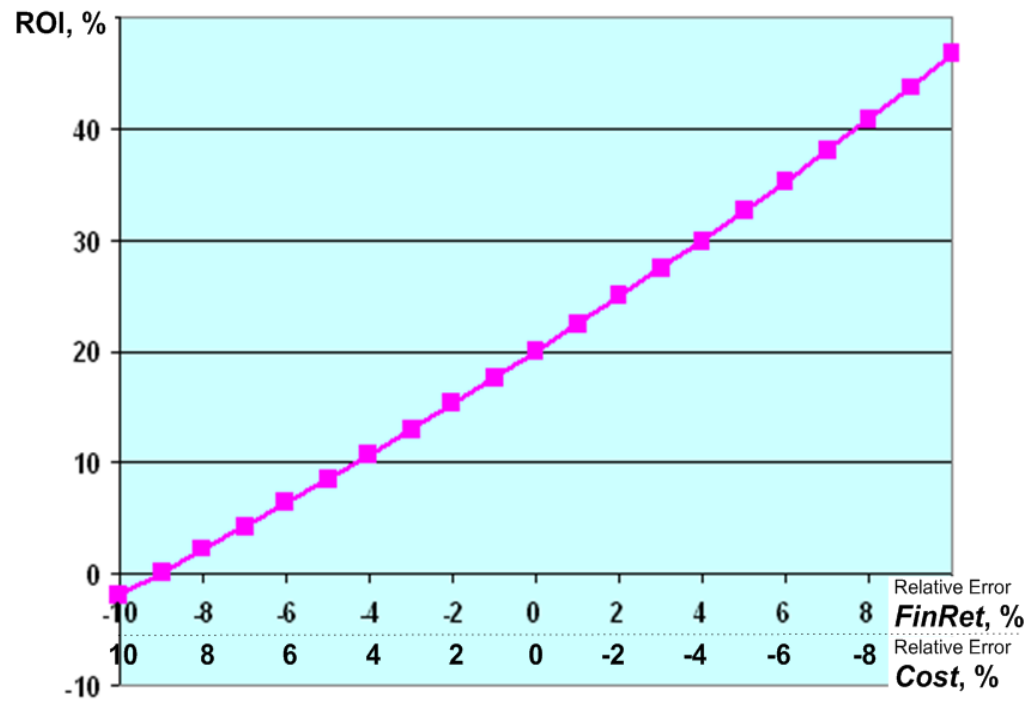

Figure 3: ROI Sensitivity to Error (worst case scenario) ROI Virtualizations

The main differentiator of ROI Virtualizations is the inclusion of intangible returns/benefits in ROI calculations. These are shown as \$B in the formula. See Table 1 for the characteristics of this ROI type. 


\section{Intangible Benefits - Examples}

Intangibles are benefits that are difficult to measure and assign a monetary value. For example, Hao, Jager, Cheng, and Hulten (2011) suggest that intangible assets can be broken down into three groups: computerized information, innovative property, and economic competencies.

Some examples of intangibles include the following (Kasabian, 2009; Mogollon \& Raisinghani, 2003; National Association of Chronic Disease Directors, 2009).

- Better information - Information systems are intended to provide relevant information for decision-making, contributing to better decisions, and therefore enhancing the return on investment.

- More timely information.

- Accurate and faster access to data for timely decisions.

- Uniform reporting according to corporate standards.

- Improved effectiveness of decision-making processes facilitating:

- Strategic planning and operations.

- Resource control and asset utilization.

- Organizational planning.

- Organizational flexibility and transparency.

- Increased productivity and time savings.

- Increased intellectual capital.

- Enhanced employee goodwill.

- Increased job satisfaction.

- Higher customer satisfaction.

- Better corporate image.

Examples shown above indicate a wide variety of types of intangibles - the "level of intangibility" is different. Some of them are easier to measure through the relation to some other parameters that are considered to be measurable, e.g., time or productivity. For others, such a "proxy" is difficult to identify.

Even the border between intangibles and tangibles is fuzzy. The same type such as "labour cost savings" may represent two significantly different entities:

- Tangible. For example, in a Traditional ROI "labour cost savings" due to a reduction of three FTE positions - resulting in real hard/tangible amount of $\$ 210,000$ dollars.

- Intangible. "Labour cost savings" of 6 min per day for 200 people. Numerically it is the same savings of 111.75 hours per week with $\$ 210,000$ "saved" annually. However, realization of this amount is more than questionable.

Intangibles need to be analyzed in the contexts of specific cases. What can be immeasurable for one case (information system/environment) can become tangible in another. 


\section{Reasons to Include Intangibles}

There are many solutions/projects that create more value than can be measured in dollars, and there is a common understanding that the value of the information systems goes far beyond the tangible benefits.

Generally speaking, the notion of intangibles is much wider than it is used in the ROI assessments. A broad discussion has been going on for the last 15 to 20 years on whether intangible assets should be included in corporate financial statements (Cleary, Kennedy, O'Donnell, O'Regan, \& Bontis, 2007; "Intangible Assets," 2011; Sveiby, 2001). It is stimulated by the results of research at different economic levels showing that intangible assets are presenting a significant and ever growing segment of the overall market value. A summary of the pros and cons of accounting for intangible assets is presented in Table 4.

Another, subjective, reason to include intangibles is that in many cases ROI of information systems based on hard dollars ("tangible" benefits) is not high enough to justify investment decisions or just equals zero (Andolsen, 2004).

Finally, the most extensive use of intangibles can be observed in the cases where ROI is given a role of the overarching performance metric. Intangibles in such cases cover a very broad range from financial benefits/returns that cannot be easily measured to any perceived value, e.g., better information.

Table 4: Inclusion of Intangibles.

\begin{tabular}{|c|c|}
\hline PROS & CONS \\
\hline $\begin{array}{l}\text { On the macro level, US investment in intangibles } \\
\text { ( } \$ 1.6 \text { trillion in 2007) has been exceeding tangible } \\
\text { investment since 1996, reflecting a shift from a } \\
\text { manufacturing to knowledge-based economy (Hao } \\
\text { et al., 2011). Same trend exists in other developed } \\
\text { countries. } \\
\text { In } 2000 \text { s, US financial sector earned over } 40 \% \text { of } \\
\text { the domestic corporate profits (Johnson, 2009). }\end{array}$ & $\begin{array}{l}\text { Macro level assessments lack structured } \\
\text { definition of intangibles. Summing up R\&D } \\
\text { investments (which may result in an abso- } \\
\text { lutely tangible product) and value of new } \\
\text { products in the financial industry (especially } \\
\text { in the wake of 2008), doubtfully may lead } \\
\text { to a convincing conclusion. }\end{array}$ \\
\hline $\begin{array}{l}\text { On the company level, the value of accumulated } \\
\text { intangible assets is comparable or even greater than } \\
\text { the book value of other assets (e.g., for Microsoft in } \\
2006 \text {, intangible assets amounted to } \$ 66 \text { billion in } \\
\text { addition to the } \$ 70 \text { billion assets on the balance } \\
\text { sheet) (Hao et al., 2011). }\end{array}$ & $\begin{array}{l}\text { Company level intangibles (e.g., value of } \\
\text { the corporate image) are prone to frequent } \\
\text { (if not daily) variations. For example, BP } \\
\text { (British Petroleum) corporate image a day } \\
\text { before and after the Gulf spill in } 2010 \text { will } \\
\text { have a significantly different value. That } \\
\text { makes the use of intangibles justifiable only } \\
\text { during a time-limited process of company } \\
\text { acquisition. }\end{array}$ \\
\hline
\end{tabular}


"Responsible ROI analysis demands that all factors be quantified in money terms. Whether recognized or not, the decision maker is placing a quantified monetary value on the intangible benefits... Thus for example, putting a dollar value on relieving pain and suffering may seem impossible and even inappropriate; but every day, health care providers make thousands of such determinations when allocating limited resources among competing demands" (Goldsmith \& Sarno, 2009).

Politicians are putting a dollar value to the lives of people setting certain value to terror security systems.

Aircraft designers are putting a dollar value on lives of passengers by embedding certain level of reliability.
Quantification of certain values (e.g., value of the project team members' collaboration provided by a new information system) and translating them into financial terms are prone to subjective judgment and inaccuracies. Resulting numbers have a false impression of rigor.

At present, the academic discussion on intangibles goes on with some gains for intangible proponents; still this discussion is far from being over. Healthy conservatism in accounting practice warrants a long time before intangibles can become an official component of financial statements (except for corporate acquisition transactions). Despite this scientific uncertainty and unwillingness of financial practitioners to embrace intangibles, inclusion of intangibles in ROI assessments has become a common practice.

\section{Sample ROI Claims Analysis}

A common starting point for ROI assessments involving intangibles is making "a conservative estimate" that a new information system will save, for example, five minutes per employee per day. These savings may result from increased employee productivity, better collaboration between project team members, reduced sales cycles, etc. After this estimate is made, the ROI assessment process is reduced to a straightforward calculation: five minutes multiplied by the salary savings of several hundred people and taken over a period of three years produce convincing numbers of "intangible benefits" and hence high ROIs.

In many cases, estimates made at the initial step (5-minute savings) look reasonable or at least convey a common sense point: "Our assumptions are so conservative that even the most determined skeptic couldn't challenge them" (Ali, 2007). To build on this positive impression, authors/consultants commonly show a great willingness to further lower or discount the amounts of intangible benefits by adding ratios of "partial capturing the benefits" (e.g., only $70 \%$ of the intangible benefits will be captured/realized) or "incremental uptake" (e.g., for a three-year implementation project, during the first year the system will be used only by $20 \%$ of the employees, and additional $30 \%$ and $50 \%$ will be given access in the second and third years respectively; system benefits will be realized based on the portion of the employees actually using the system).

Some experts, while agreeing that not all time potentially saved will be used productively, state that lower-level employees are more likely to turn extra time into more work and offer the following rule-of-thumb percentage of time converted into increased output (Alster, 2002):

- Assembly-line workers: $95-100 \%$.

- Call-center support: 90 - 95\%.

- Administrative and support help: $70-80 \%$. 
- Engineering (technical): $75 \%$.

- Engineering (non-technical): $65-75 \%$.

- General staff within a group (marketing, PR, accounting): $60 \%$.

- Companywide general staff: $50 \%$.

- Middle management (large corporations): 40 - 55\%.

The above "concessions" to the opponents of the inclusion of the intangibles are offered not only to make results look more realistic, but also to divert attention from the foundational questions about the initial estimate (those 5 minutes). How was this number arrived at? Why is the amount five and not three or ten minutes? What was the objective rationale behind this assessment? These questions are usually left unanswered and allow opponents of including intangibles argue that ROI assessments of intangibles can easily vary by $+/-100 \%$ or more and that such variance indicates a wide window for subjectivity and misjudgement in the results of ROI calculations.

Here are several samples of business cases which include intangible benefits.

1. ROI evaluation of Microsoft Unified Communications by Forrester. In 2007, Microsoft Corporation commissioned Forrester Consulting to evaluate potential ROI that enterprises may realize by deploying Microsoft Unified Communications (UC) products and services (including Microsoft Office Communications Server 2007, Exchange Server 2007, Office Communicator 2007, etc). Forrester conducted interviews with 15 Microsoft customers and compiled their results into a composite case study of a 4,000-person digital marketing services company (North, 2007). ROI assessments were done within a broader framework of Forrester's Total Economic Impact (TEI) evaluation.

Evaluation time frame was 3 years. Calculations were adjusted for time value of money and risk. Costs were estimated at $\$ 6$ million. Overall benefits were evaluated at $\$ 39.5 \mathrm{M}$. A snapshot of the benefits (types and approach to calculation) used for the ROI evaluations is shown in Table 5.

Both tangible $(\$ 12.4 \mathrm{M})$ and intangible $(\$ 27.1 \mathrm{M})$ benefits were included. As an example, Forrester conservatively estimated that UC can free 40 hours per year for each employee for 2,500 employees, or less than 1 hour per week per employee (North, 2007).

The amount of the ROI is $563 \%$. If intangibles were not included ROI would be $108 \%$.

Table 5: Unified Communications ROI Case Snapshot

\begin{tabular}{|l|l|l|c|}
\hline \multicolumn{1}{|c|}{ Benefits by Type } & \multicolumn{1}{|c|}{ Approach to Calculation } & $\begin{array}{c}\text { Intangible/ } \\
\text { Tangible }\end{array}$ & $\begin{array}{c}\text { Present } \\
\text { Value } \\
\text { (Million })\end{array}$ \\
\hline $\begin{array}{l}\text { 1) Increased productivity } \\
\text { by communicating more } \\
\text { efficiently and faster. }\end{array}$ & $\begin{array}{l}\text { Multiply: Number of workers; Hourly rate } \\
\text { per worker; Adoption rate; Number of } \\
\text { hours (saved) - 40 to 100 per year based } \\
\text { on the user group; Percent captured. }\end{array}$ & Intangible & $\$ 13.4$ \\
\hline $\begin{array}{l}\text { 2) Reduced time to com- } \\
\text { plete projects. }\end{array}$ & $\begin{array}{l}\text { Multiply: Net revenue of project; Gross } \\
\text { margin \%; Project per year; Percent of pro- } \\
\text { ject time reduced due to improved col- } \\
\text { laboration - 10\%; Percent of time saved } \\
\text { that could be applied to other projects; } \\
\text { Adoption rate. }\end{array}$ & Intangible & $\$ 10.3$ \\
\hline
\end{tabular}




\begin{tabular}{|c|c|c|c|}
\hline Benefits by Type & Approach to Calculation & $\begin{array}{c}\text { Intangible/ } \\
\text { Tangible }\end{array}$ & $\begin{array}{l}\text { Present } \\
\text { Value } \\
\text { (Million ) }\end{array}$ \\
\hline 3) Shortened sales cycle. & $\begin{array}{l}\text { Multiply several parameters, including: } \\
\text { Percent of time saved through more ef- } \\
\text { fective internal communication, reducing } \\
\text { delays in the proposal process }-\mathbf{2 0 \%} \text {. }\end{array}$ & Intangible & $\$ 3.4$ \\
\hline 4) Travel cost reductions. & & Tangible & $\$ 11.1$ \\
\hline $\begin{array}{l}\text { 5) Reduced costs of dial- } \\
\text { ing pay-per-minute tele- } \\
\text { phone conferencing. }\end{array}$ & & Tangible & $\$ 0.5$ \\
\hline $\begin{array}{l}\text { 6) Reduced long-distance } \\
\text { telephone charges. }\end{array}$ & & Tangible & $\$ 0.8$ \\
\hline Subtotal Intangible & & & $\$ 27.1$ \\
\hline Subtotal Tangible & & & $\$ 12.4$ \\
\hline Total & & & $\$ 39.5$ \\
\hline
\end{tabular}

2. ROI evaluation of the MarkView suite by The Gantry Group. The MarkView Financial Suite automates financial processes to ensure consistent, efficient, cost-effective, and timely processing of all transactions.

The Gantry Group found that the MarkView suite generated an average three-year ROI of 332 percent, or \$1.9 million, with an average payback of 7.4 months (MarkView for Accounts Payable, n.d.).

3. ROI evaluation of the Force.com by IDC Research. Force.com customers have built 185,000 apps $85 \%$ faster, with an ROI of $721 \%$ and a $54 \%$ lower TCO, as stated in an e-mail invitation for a webinar on January 21, 2011 sent by the SalesForce.com.

4. ROI evaluation of the Soffront. Soffront works on optimizing companies' productivity by eliminating the hassle and cost of searching, reviewing, watching hours of demos, pricing and interviewing third party suppliers. An ROI study relating to successful CRM implementations found companies have yielded returns ranging from $16 \%$ to more than $1,000 \%$ ! as stated in an email "Save money, avoid hassles" from Soffront on February 26, 2011.

Sample cases shown above demonstrate that ROIs with magnitudes of $300-700 \%$ became common and widely published in the business literature. This level of ROI numbers testifies that this measure has little, if anything, in common with a traditional ROI - an important financial metric.

\section{Intangible Costs}

In the general discussions about intangibles, participants take as given that there are not only intangible benefits but also intangible costs (costs that are difficult/impossible to predict and/or quantify). However, rarely are intangible costs included in the ROI calculations.

Some examples of intangible costs are ("What are some," n.d.):

- Cost of upsetting customers from system change.

- Cost of failure due to inappropriate system or faulty implementation. 
- Incompatibility with other systems leading to unexpected costs of software amendments, tailoring, and maintenance.

- Cost of errors due to lack of experience in using new system (IT dept, users).

- Cost of losing staff morale.

- Cost of losing a competitive edge.

- Cost of declining company image.

- Loss of investment in prior systems.

A known J-curve showing a temporary drop in productivity associated with a change (implementation of a new information system and business processes) is presented in Figure 4.

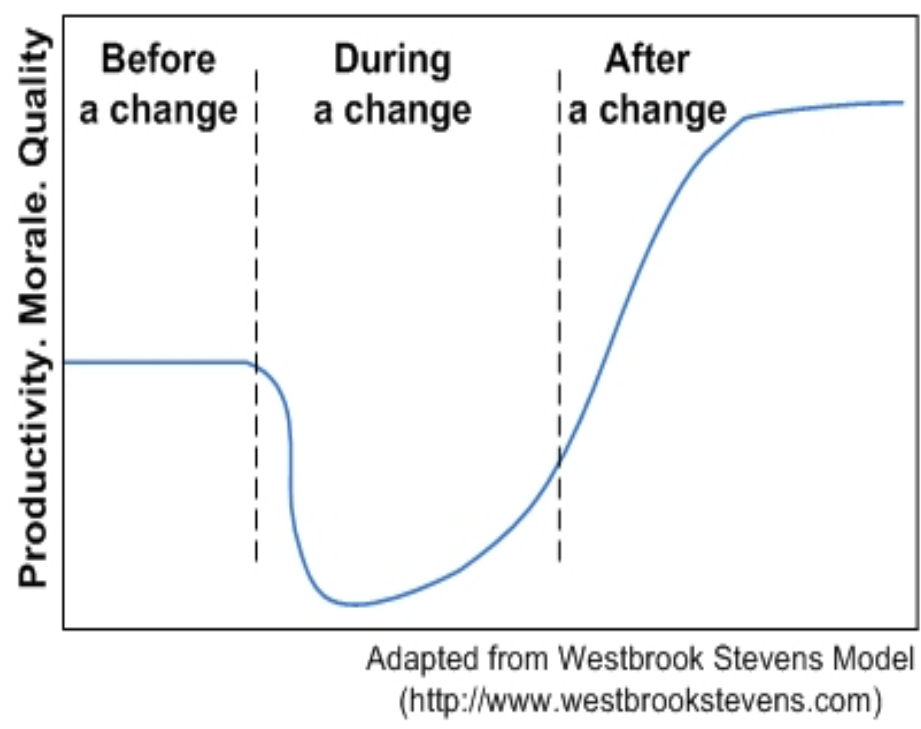

Figure 4: A J-curve of temporary drop in productivity

Intangible costs do exist and affect the introduction of information systems. For consistent application of the ROI virtualizations, these costs should be factored in.

\section{ROI Virtualizations Wrap-up}

The use of intangibles is not an "internal" ROI issue. Research in the area of intangibles, their quantification, and their evaluation is an important effort. However, this area of research is far from being completed, and results are not yet ready for use in regular business (accounting) practice.

Until financial professionals recognize and use intangibles for accounting purposes, any ROI calculations and results should explicitly provide not only overall ROI but ROI for "hard" dollars and ROI with intangibles included.

As defined in the beginning of this section, intangibles are benefits and costs that are difficult to measure and assign a monetary value, but it is not impossible. Another position is that the term intangible should refer only to the benefits that are impossible to measure (e.g., better corporate image), and the benefits that are difficult to measure should be grouped in a separate class - called soft benefits (Hubbard, 2010). 
Currently, what we term ROI virtualizations are intended to leave an impression of objective and mathematically sound analysis and results, while in reality they are mostly based on subjective perceptions, prone to inaccuracies and falsifications.

The inclusion of intangible benefits makes a false promise/impression that ROI as a measure has a broad nature that provides an overarching description of the performance of the information system and business as a whole, while in reality it still characterizes only a certain aspect of a financial area.

\section{ROI Imitations}

ROI imitations can be classified into two subcategories:

- Subcategory 1. Use of the ROI term for measures which have little or nothing to do with ROI. The purpose is to cash in on the seemingly positive credibility of the ROI term.

- Typical for this group of measures is an understanding of ROI as "any benefit/value," for example, Notional ROI (Bigham \& Goudreau, 2004) and Public ROI (Al-Raisi \& Al-Khouri, 2010).

- Imitations are taking ROI even further afield from the traditional financial understanding of it than the Virtualizations.

- Subcategory 2. Paradoxically enough, this group attempts NOT to use the ROI term (at least in the titles). They actually use ROI method or a very similar method under different names claiming that they've overcome the ROI deficiencies/limitations, for example stating that their measures are multi-dimensional.

\section{Discussion}

A notable point regarding ROI is that an estimated amount has meaning only within the business situation for which it was calculated. Each ROI business case includes costs and returns that are specific to the situation under investigation.

For example, a business case ("ROI case study," 2007) indicates that implementation of the Google Apps for the TVR company had ROI of 500\%. Despite the discussion on ROI accuracy above, let's assume that this number is absolutely precise for the case. That doesn't mean that any other company which is planning on implementing Google Apps can use this number $(500 \%)$ in their assessments/decisions or can expect having ROI anywhere close to this number as such considerations are inapplicable. In the referenced case, financial returns were partially based on the cost avoidance of switching from the outdated version of MS Exchange run on Windows NT to a newer version. For any other case, this benefit component will be inapplicable. The value of the ROI calculations provided by applications vendors within marketing materials are not in the ROI amounts cited but in the description of the components included, so that the assessment process could be recalculated by a potential client for its own situation.

For information systems such as ERP and CRM, a certain amount of costs and an even larger part of returns are determined by the way the business processes have been set up. In most cases, this set up is individual for a company.

To conclude the above considerations, ROI numbers are not attributes of a specific application or solution. Also, ROI numbers calculated at different companies are incomparable.

Earlier we mentioned a notion of the "negative" ROI and a straightforward business opinion namely, projects with negative ROI should not be approved (Heerkens, 2010). However, what if a ROI-negative project: 
- Enables transition to a new profitable business area (which will not be realized within this specific project/timeframe)?

- Ensures company's sustainability in an important market to offset competition?

- Supports commitment to regulatory compliance.

There are no simple answers to these questions, and ROI is not designed to address these issues. As pointed out in "Achieving measurable ROI for IT..." (2004), a business imperative might never have a positive ROI - instead, the best initiative will be the one with the least negative ROI.

Throughout the paper, the authors have maintained an objective view on ROI and discussed its strengths and limitations. The fact that certain ROI deficiencies as a metric are explicitly identified doesn't mean that the authors are recommending not using ROI. The point here is that too often ROI is used in the evaluation of information systems and perhaps too much weight is placed on it.

ROI is just one of many metrics for evaluating information systems. As mentioned in the Introduction, there are many other popular financial measures, and even more metrics of different (non-financial or complex) types. We'll briefly mention only the most popular:

- Economic Value Added (EVA) (“Economic Value Added,” n.d.). A measure of a company's financial performance based on the residual wealth calculated by deducting cost of capital from its operating profit (adjusted for taxes on a cash basis). The measure was devised by Stern Stewart \& Co. EVA attempts to capture the true economic profit of a company. As with many metrics, it's hard to link precise EVA returns to a specific technology investment. EVA is ideally suited to publicly traded companies, not private companies, because it deals with the cost of equity for shareholders, as opposed to debt capital.

- Total Economic Impact (TEI) developed by Forrester Research Inc. (Total Economic Impact, n.d.). Forrester claims TEI systematically looks at the potential effects of technology investments across four dimensions:

- Cost - impact on IT.

- Benefits - impact on business.

- Flexibility - future options created by the investment.

- Risk - uncertainty.

Arguably, analysis of the Forrester case studies shows that the TEI-approach essentially boils down to determining ROI (with risk-adjusted, intangible benefits included in financial terms). The "Flexibility" component either was not estimated or not included in the overall cost/benefit numbers.

- Business Value of IT (ITBV) Program was developed by Intel Corporation in 2002 (Sward, 2006). The program uses a set of financial measurements of business value that are called Business Value Dials (Indicators). It is a Multidimensional program, including a business component, and is relatively easy to implement.

- Val IT is a framework for the governance of IT investments developed by The IT Governance Institute (ITGI) ("Val IT framework," n.d.), the originator of the COBIT (Control Objectives for Information and related Technology). Val IT is aligned with COBIT Version 4 and provides:

- $\quad$ a set of guiding principles, and 
- a number of processes conforming to those principles that are further defined as a set of key management practices.

Val IT includes several dozen practices in the three domains:

- Value Governance

- Portfolio Management

- Investment Management

- Applied Information Economics (AIE) is a decision analysis method developed by Hubbard Decision Research (Hubbard, 2010). AIE claims to be "the first truly scientific and theoretically sound method" that builds on several methods from decision theory and risk analysis including the use of Monte Carlo methods. AIE is not used often because of its complexity.

Comparison of a variety of these methods is out of scope of this paper, but these topics may be of interest to readers wishing to explore other methodologies.

\section{Conclusions and Recommendations}

The conclusions and recommendations of this paper are to be considered in the context of this study, which is that they pertain to information systems in the meaning defined in the beginning of the article. The conclusions may or may not be applicable to many other vast and diverse fields where ROI is used.

1. An ROI taxonomy has been developed which includes four ROI types: traditional ROI, extensions, virtualizations, and imitations. This taxonomy provides a conceptual framework for ROI analysis and evaluating quantitative results.

2. ROI has been conceived as a financial term and concept and should be used as such. If there is a need for another measure that doesn't fit the original ROI concept, it is better to use another term(s) to avoid confusion or multiple meanings for "ROI", "returns", and "investments".

3. ROI is a metric designed for a certain purpose - to evaluate profitability or financial efficiency. It cannot reliably substitute for many other financial metrics in providing an overall economic picture of the information solution.

4. ROI is not a single number. It has been demonstrated that ROI being presented as a single number has many uncertainties and limitations which make the single number actually meaningless.

To provide a meaningful context for business decisions, the ROI number must be accompanied with a detailed description of the terms, conditions, and assumptions under which the ROI calculations were conducted and at least 5 to 10 additional numeric characteristics of the ROI business case.

5. The perceived or implied rigor of the whole ROI process and results can be inappropriate and may lead to over-confidence in a complex situation. ROI error sensitivity assessment has shown that even relatively low-level errors of estimating costs and returns (+/- 10\%) may lead to significant ROI inaccuracies. Any ROI number should be provided with an assessment of its accuracy.

6. Until financial professionals recognize and use intangibles for accounting purposes, any ROI calculations and results should explicitly provide not only overall ROI but ROI for "hard" dollars and ROI with intangibles included. 
7. There's a need for a standard or guidelines to formalize requirements for data collection, calculations, and forms of presenting ROI evaluations.

8. The attempts at using ROI as the sole or principal metric for decision making regarding information systems cannot be productive. It may be appropriate in a very limited number of cases/projects. ROI is a financial measure and does not provide information about efficiency or effectiveness of the information systems.

9. Evaluation of information systems is a multi-dimensional and multi-criteria task. A variety of evaluation metrics have been developed, and evaluators need to do due diligence while selecting appropriate metrics for a specific case. Most likely, a set of metrics will be required to evaluate a system, and ROI should be considered for incorporation in the overall performance measurement framework.

\section{Acknowledgements}

The views, opinions and conclusions expressed in this document are those of the authors alone and do not necessarily represent the views of the Ontario Ministry of Health and Long-Term Care or any of its individual departments.

\section{References}

Achieving measurable ROI for IT: There must be a better way. (2004, March). AMDOCS. White Paper.

Ali, T. (2007). Seeking elusive ROI for software projects. Financial Executive, 23(3), 54-56.

Al-Raisi, A. N., \& Al-Khouri, A. A. (2010). Public value and ROI in the government sector. Advances in Management, 3(2).

Alster, N. (2002, October 15). ROI: Results often immeasurable? CFO Magazine.

Andolsen, A.A. (2004). Investing wisely for the future. The Information Management Journal, September/October, 47-54.

Armor, D.A., \& Taylor, S.E. (2002). When predictions fail: The dilemma of unrealistic optimism. In T. Gilovich, D. Griffin, \& D. Kahneman (Eds.). Heuristics and biases: The psychology of intuitive judgment. Cambridge, UK: Cambridge University Press. ISBN 0-521-79679-2.

Bigham, J. D., \& Goudreau, T. R. (2004). Return on investment in the public sector. MBA Thesis. Naval Postgraduate School, Monterey, California.

Chmielewski, T. L., \& Phillips J. J. (2002). Measuring return-on-investment in government: Issues and procedures. Public Personnel Management, 31(2), 225-237.

Cleary, P., Kennedy, T., O’Donnell, D., O’Regan, P., \& Bontis, N. (2007). Positioning management accounting on the intellectual capital agenda. International Journal of Accounting, Auditing and Performance Evaluation, 4(4/5), 336-359.

Coelho, P.S., \& Vilares, M.J. (2010). Measuring the return of quality investments. Total Quality Management, 21(1), 21-42.

Dearden, J. (1969). The case against ROI control. Harvard Business Review, 47(3), 124-135.

Economic Value Added - EVA. (n.d). In Investopedia. Retrieved May 9, 2011, from http://www.investopedia.com/terms/e/eva.asp

Goetzel, R. Z. (n.d.). Expert interview. Retrieved from http://www.cdc.gov/leanworks/assess/expert.html

Goldsmith, R. F., \& Sarno, A. (2009). 10 ROI pitfalls. Go Pro Management. White Paper. Retrieved from http://www.softwareceo.com/downloads/file/sceo/white_papers/ProveIT_WP_10_ROI_pitfalls_709.pd $\underline{\mathrm{f}}$ 
Haddad, R. (2011). From ROI to VOI: Organizations are failing to tie learning to business impact. Project Manager Today, January/February, 22-25.

Hall, M. (2003, February 17). Forget ROI. Computerworld. Retrieved from http://www.computerworld.com/action/article.do?command=viewArticleTOC\&specialReportId=180\& $\underline{\text { articleId }=78516}$

Hao, J. X., Jager, K., Cheng, B., \& Hulten, C. R. (2011). Innovation and intangible assets. The Conference Board, Executive Action Series, January, No. 341.

Heerkens, G. R. (2010). In praise of ROI. PM Network, 24(5), 23.

Hirsch, S., Fraser, J., \& Beckman, S. (2004). Leveraging business value: How ROI changes user experience. Adaptive Path LLC.

Hubbard, D. (2010). How to measure anything: Finding the value of intangibles in business (2nd ed.). John Wiley \& Sons.

Intangible Assets. (2011). The Conference Board. Retrieved May 9, 2011, from http://www.conferenceboard.org/data/intangibles

Johnson, S. (2009, May). The quiet coup. The Atlantic.

Kalvar, S. T. (2003, July 28). Apply ROI as a persuasive communication method--not just analysis. TechRepublic. Retrieved May 9, 2011, from http://articles.techrepublic.com.com/5100-10878 11$\underline{\text { 5055006.html }}$

Kasabian, D. (2009). Funding for BI: It's all about ROI, ROI, ROI. IBM Cognos.

Kingma, B., \& Schisa, K. (2010). WISE economics: ROI of quality and consortiums. Journal of Education for Library and Information Sciences, 51(1), 43-52.

MarkView for Accounts Payable. (n.d.) Retrieved May 9, 2011, from http://www.kofax.com/markview/internal-controls.asp

Maximizing website return on investment. (2009). Google White Paper.WP47-0902.

McManus, D. J., Wilson, L.T., \& Snyder, C. A. (2004). Assessing the business value of knowledge retention projects: Results of four case studies. Proceedings of the 2004 IFIP International conference on Decision Support Systems (DSS2004).

Mogollon, M., \& Raisinghani, M. (2003). Measuring ROI in e-business: a practical approach. Information Systems Management, 20(2), 63-81.

National Association of Chronic Disease Directors (2009). A practical guide to ROI analysis. Retrieved May 9, 2011, from http://www.chronicdisease.org/professionaldevelopment/documents/roi/ROI.pdf/view

North, J. (2007). The total economic impact of Microsoft unified communications products and services. Microsoft website. Retrieved May 9, 2011, from http://www.microsoft.com/downloads/en/details.aspx?FamilyID=4f93880c-4667-4fbc-bea5$\underline{\mathrm{e} 510 \mathrm{~b} 3 \mathrm{~b} 95 \mathrm{c} 4 \mathrm{e} \& \text { displaylang=en }}$

North, J. (2009). The total economic impact of salesforce CRM customer service \& support. Forrester Consulting, Retrieved May 9, 2011, from https://www.salesforce.com/assets/pdf/misc/WP Forrester_Eco_Impact.pdf

Petouhoff, N. L. (2009, May27). The ROI of social media: Customer service communities. Social Media Club, Forrester Research.

Phillips, P. P., \& Phillips, J. J. (2006). Measuring ROI in the public sector. In Action Case Study Series. ASTD Press.

Project Management Institute. (2008). A guide to the project management body of knowledge (PMBOK Guide) (4th ed.) 
Rate of return. (n.d.). In Wikipedia. Retrieved May 9, 2011, from http://en.wikipedia.org/wiki/Rate_of_return

Return on investment. (n.d.). In SearchCIO.com. Retrieved May 9, 2011, from http://searchcio.techtarget.com/resources/Return-on-investment

Return on investment - ROI. (2011). In Investopedia .Retrieved May 9, 2011, from http://www.investopedia.com/terms/r/returnoninvestment.asp

ROI case study Google apps TVR communications. (2007, January). Nucleus Research. Document I117.

Ryan, R., \& Raducha-Grace, T. (2009). Business of IT: How to improve service and lower costs. IBM Press. ISBN-10: 0-13-701890-8.

Sveiby, K-E. (2001). Methods for measuring intangible assets. Sveiby Knowledge Associates website, updated 2010. Retrieved May 9, 2011, from http://www.sveiby.com/articles/IntangibleMethods.htm

Sward, D. (2006). Measuring the business value of information technology. Practical strategies for IT and business managers (IT Best Practices). Intel Press.

Total Economic Impact. (n.d.) Forrester Research Inc. website. Retrieved May 9, 2011, from http://www.forrester.com/TEI

Val IT framework for business technology management. (n.d.) Retrieved May 9, 2011, from http://www.isaca.org/Knowledge-Center/Val-IT-IT-Value-Delivery-/Pages/Val-IT1.aspx

Weinstein, N. D. (1980). Unrealistic optimism about future life events. Journal of Personality and Social Psychology, 39(5), 806-820.

What are some intangible costs for information systems? (n.d.) In Answers.com. Retrieved May 9, 2011, from

http://wiki.answers.com/Q/What_are_some_intangible_costs_for_information_systems\#ixzz1FB4MR $\underline{\text { GVT }}$

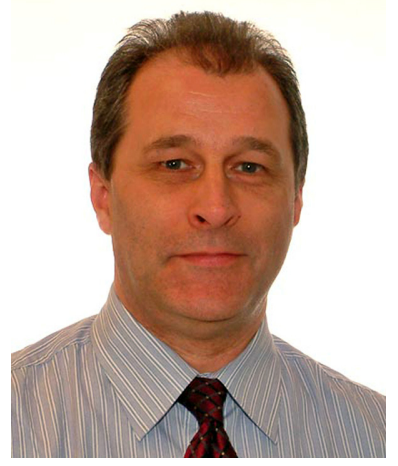

\section{Biographies}

Alexei Botchkarev is a Senior Information Management Advisor with the Knowledge Management Branch, Ministry of Health and LongTerm Care (Government of Ontario), and an Adjunct Professor at Ryerson University, Department of Computer Science. He is an information and knowledge management professional, consultant and researcher (www.gsrc.ca). He has over 30 years of experience in project management, systems analysis, modelling and simulation, business processes analysis, information systems solutions, and requirements analysis. He holds B.Eng. 5-year degree from the Kiev Aviation Engineering Academy, Ukraine and Ph.D. from the aerospace R\&D Institute. Dr. Botchkarev is active with IEEE and several other professional organizations.

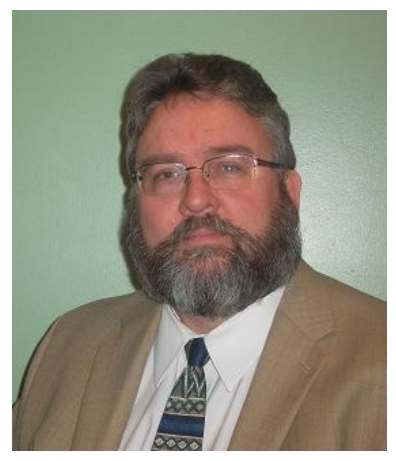

Peter Andru is a Manager with the Knowledge Management Branch, Ministry of Health and Long-Term Care (Government of Ontario). He has 20 years of experience in healthcare and government programs, project management, decision support, and information systems. He holds a Master of Science from the University of British Columbia. 